\title{
International Handbook of \\ Behavior Modification and Therapy
}

STUDENT EDITION 


\section{International Handbook of Behavior Modification and Therapy \\ STUDENT EDITION}

Edited by

Alan S. Bellack

Medical College of Pennsylvania at EPPI

Philadelphia, Pennsylvania

\section{Michel Hersen}

and

Alan E. Kazdin

Western Psychiatric Institute and Clinic

University of Pittsburgh School of Medicine

Pittsburgh, Pennsylvania 
Library of Congress Cataloging in Publication Data

Main entry under title:

International handbook of behavior modification and therapy.

Includes bibliographical references and index.

1. Behavior therapy-Handbooks, manuals, etc. 2. Behavior modification-Handbooks, manuals, etc. I. Bellack, Alan S. II. Hersen, Michel. III. Kazdin, Alan E.

RC489.B4I54 1985

616.89'142

$84-22652$

ISBN-13: 978-1-4615-7280-0

DOI: $10.1007 / 978-1-4615-7278-7$

This book contains thirteen selected chapters originally published in the International Handbook of Behavior Modification and Therapy (1982).

(C) 1985, 1982 Plenum Press, New York

A Division of Plenum Publishing Corporation

233 Spring Street, New York, N.Y. 10013

All rights reserved

No part of this book may be reproduced, stored in a retrieval system, or transmitted in any form or by any means, electronic, mechanical, photocopying, microfilming, recording, or otherwise, without written permission from the Publisher 
Walter and Natalie

Victoria, Gordon, and Helen

Alan, Michael, Daniel, and Steven 


\section{Preface to Student Edition}

The reaction to the International Handbook of Behavior Modification and Therapy has been most enthusiastic. We are gratified by the many positive comments provided by noted behavior therapists with whom we have no affiliation, as well as those from friends and colleagues. Our hypothesis about the need for a comprehensive reference was, apparently, accurate. Moreover, we were fortunate enough to secure a stellar list of contributors who submitted a set of uniformly excellent chapters, many of which have quickly become key references on their respective topics. In addition to the positive feedback, one concern has frequently been brought to our attention. Several colleagues have expressed their regret that the book cannot readily be used as a text in graduate courses, that it is too extensive to be covered in a single graduate seminar. Hence, graduate students may not have ready access to the material.

With that concern in mind, we have constructed the current shortened version. We have selected 13 chapters that comprise a representative curriculum for an introductory graduate seminar on behavior therapy. The chapters comprise three general sections: General Issues, which reflect core principles and practices (history, theory, assessment, and single case research); Treatment of Adult Disorders (anxiety, fear, depression, schizophrenia, medical disorders, and interpersonal problems); and Treatment of Childhood Disorders (behavior problems in the home and classroom, mental retardation, and medical disorders). Each chapter is reprinted in its entirety from the complete Handbook. Naturally, this shortened version has excluded several notable topics. However, we felt it wiser to present the complete text of chapters on key topics than to condense many chapters in order to cover more topics. Our view is that graduate students would profit more from in-depth coverage of the various literatures than a more superficial overview of the entire field.

In addition to the individuals mentioned in the Preface to the complete volume, we would like to thank Eliot Werner for his help on this edition, as well as numerous other projects.

Alan S. Bellack Michel HERSEN Alan E. KaZDiN 


\section{Preface to First Edition}

The rapid growth of behavior therapy over the past 20 years has been well documented. Yet the geometric expansion of the field has been so great that it deserves to be recounted. We all received our graduate training in the mid to late 1960s. Courses in behavior therapy were then a rarity. Behavioral training was based more on informal tutorials than on systematic programs of study. The behavioral literature was so circumscribed that it could be easily mastered in a few months of study. A mere half-dozen books (by Wolpe, Lazarus, Eysenck, Ullmann, and Krasner) more-or-less comprised the behavioral library in the mid1960s. Seminal works by Ayllon and Azrin, Bandura, Franks, and Kanfer in 1968 and 1969 made it only slightly more difficult to survey the field. Keeping abreast of new developments was not very difficult, as Behaviour Research and Therapy and the Journal of Applied Behavior Analysis were the only regular outlets for behavioral articles until the end of the decade, when Behavior Therapy and Behavior Therapy and Experimental Psychiatry first appeared.

We are too young to be maudlin, but "Oh for the good old days!" One of us did a quick survey of his bookshelves and stopped counting books with behavior or behavioral in the titles when he reached 100. There were at least half again as many behavioral books without those words in the title. We hesitate to guess how many other behavioral books have been published that he does not own! Another of us subscribes to no less than 10 behavioral journals. A quick count indicated that there are at least 6 others. Moreover, such nonbehavioral publications as Journal of Consulting and Clinical Psychology, Clinical Psychology Review, and Psychological Bulletin sometimes appear to be more behavioral than anything else.

Needless to say, it is no longer possible to be up-to-date with the entire field. In fact, it is difficult to follow all of the literature in some popular subareas (e.g., behavioral medicine and cognitive behavior therapy). This information overload has a number of undesirable consequences in the research and practice of behavior therapy. It also has a pragmatic implication. Unless one is a prolific book-buyer and journal-subscriber, it is no longer even possible to have a comprehensive behavioral reference library.

Most books currently available fall into one of two classes: elementary surveys (e.g., textbooks) or narrow, highly specialized volumes. Neither type of book meets the need of most professionals for a convenient source of sophisticated 
reviews. There has been no resource for the person who must get a current but general picture of an area outside of his or her area of specialization. The need for such a resource served as the stimulus for this handbook. Our intention is to provide a basic reference source, in which leaders in the field provide up-to-date reviews of their areas of expertise. Each chapter is intended to give an overview of current knowledge and to identify questions and trends that will be important in the field during the next decade.

In developing the outline for the book, it quickly became apparent that it was impossible to include chapters on every topic studied by behavior therapists. Many readers will find omissions or imbalances in what they regard as vital areas. We have tried to represent major areas of interest and effort. The behavior change chapters, in particular, cover areas that have been subjected to extensive research, rather than areas in which major problems have been solved or exciting new areas with little support as yet. We have also chosen to focus on behavior problems rather than on techniques or models. While many behavior therapists identify with techniques or models (e.g., cognitive behavior therapy), they generally focus on specific problems (e.g., depression and chronic patients). Similarly, the general reader is more likely to be interested in the best treatment for a particular problem than in an overview of a general strategy.

A work of this scope requires the diligent efforts of a great number of people. We would like to thank the contributors for producing a set of uniformly excellent manuscripts. Special appreciation is extended to Mary Newell, Claudia Wolfson, and Lauretta Guerin for their matchless secretarial assistance. Finally, we express our gratitude to our friend and editor, Len Pace, who served a central role in this project from beginning to end.

Alan S. Bellack

Michel Hersen

Alan E. Kazdin 


\section{Contents}

\section{PART I GENERAL ISSUES}

Chapter 1 History of Behavior Modification . . . . . . . . . . . . 3

Alan E. Kazdin

Chapter 2 Experimental and Theoretical Foundations of Behavior Modification . . . . . . . . . . . . . . . . . . . . 33

Donald J. Levis

Chapter 3 Behavioral Assessment: An Overview _. . . . . . . . . 57

Marvin R. Goldfried

Chapter 4 Single-Case Experimental Designs . . . . . . . . . . . . 85

Michel Hersen

\section{PART II ADULT DISORDERS}

Chapter 5 Anxiety and Fear . . . . . . . . . . . . . . 125

Paul M. G. Emmelkamp 
Peter M. Lewinsohn and Harry M. Hoberman

Chapier 7 Treatment of Schizophrenia _. . . . . . . . . . . . . 209

James P. Curran, Peter M. Monti, and Donald P. Corriveau

Chapter 8 Adult Medical Disorders . . . . . . . . . . . . . 243

C. Barr Taylor

Chapter 9 Interpersonal Dysfunction _. . . . . . . . . . . . 277

Alan S. Bellack and Randall L. Morrison

\section{PART III CHILDHOOD DISORDERS}

Chapter 10 The Modification of Child Behavior Problems

in the Home . . . . . . . . . . . . . . . . . . . . . 311

Beth Sulzer-Azaroff and Martin J. Pollack

Chapter 11 Behavior Analysis Procedures in Classroom Teaching . . . 353

Ted R. Ruggles and Judith M. LeBlanc

Chapter 12 Retardation .................. 391

John T. Neisworth and Ronald A. Madle

Chapter 13 Treatment of Childhood Medical Disorders . . . . . . . . 429

Daniel M. Doleys and Jan Bruno

Author Index . . . . . . . . . . . . . . . . . . . . . . . . . . . 449

Subject Index . . . . . . . . . . . . . . . . . . . . . . . . . . . 469 